Papagei mit. Die in dem Artikel behauptete acute Wirkung des Tuberkulose-Bacillus wird durch Herrn Dr. $\mathrm{K} \mathrm{r}$ a e $\mathrm{m}$ er angezweifelt.

Herr Schalow spricht über den seiner Zeit bereits von Herrn v o n Dallwitz erwähnten, im Wohlauer Kreise bei Mönchmotschelwitz erlegten Jagdfalken. Das Exemplar, welches für das Kgl. Museum für Naturkunde angekauft worden ist, hat sich als ein Weibchen im Übergangskleide von Falco rusticulus L. herausgestellt. Der Vortragende hebt hervor, dass dieses Stück das zweite nachweislich in Deutschland crlegte Exemplar des norwegischen Jagdfalken darstellt. Das andere ist in der Nähe von Hamburg geschossen und von Hartert bestimmt worden. In England wurde vor circa 10 Jahren ein anderes Stäck bei Suffolk erlegt. Bisher ist nur $F$. rusticolus für Deutschland nachgewiesen, alle Mitteilungen über das Vorkommen von $\boldsymbol{F}$. islandicus und $F$. candicans innerhalb der Grenzen unseres Vaterlandes sind sehr unsicher.

Schalow.

Matschie.

\title{
Bericht über die März-Sitzung.
}

Verhandelt Berlin, Montag, den 2. März 1896. Abends 8 Uhr im Sitzungslokale, Bibliothekzimmer des Architekten-Vereinshauses, Wilhelmstr. 92. II.

Anwesend die Herren: Reich enow, Grunack, Thiele, Emcke, von Treskow, Deditius, Schenkling, Stoll, Günther, Schulz, Deichler, Brehm, Bünger, R. Rörig, G. Rörig, Krüger-Velthusen, Pascal, Matschieu.Arends. Als Gast: Herr Gotts chlag.

Vorsitzender: Herr Reichenow. Schriftf.: Herr Matschie. Nachdem die Herren Reichenow und Matschie über die während des verflossenen Monats erschienenen und eingegangenen ornithologischen Arbeiten berichtet haben, spricht Herr G. Rörig

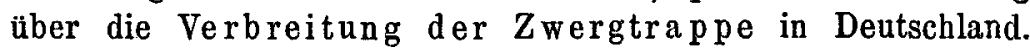
Der Vortrag, welcher in No. 47 der "Deutschen Jägerzeitung" abgedruckt ist, falst die in der Litteratur aufgezählten Mitteilungen über das Auftreten der Zwergtrappe in Deutschland zusammen.

Herr Reichenow bringt eine Petition des "Vereins zur Bekämpfung des Vogelmassenmordes" an den Reichstag zur Sprache und ist der Ansicht, dafs die Deutsche Ornithologische Gesellschaft Mafsregeln gegen die Verwendung von Vogelkörpern zu Modezwecken zustimmen könne, aber gegen weitere $\mathrm{Be}$ - 
schränkungen des Vogelfanges sich erklären müsse. Über die Abnahme der Drosseln und die Einwirkung des Dohnenstieges auf den Individuenbestand dieser Singvögel erhebt sich in der Besprechung eine Debatte, in welcher die Herren KrügerVelthusen und von Treskow die Verminderung in der Zahl unserer Singdrosseln hervorheben. In wieweit der Dohnenstieg schädlich in dieser Beziehung einwirkt, darüber sind die Meinungen unter den Anwesenden geteilt.

Herr Reichenow legt alsdann einige vom Rothschild-Museum in Tring eingetauschte seltene Vogelarten vor, unter denen sich u. a. der von A. B. Meyer vor kurzer Zeit beschriebene Paradiesvogel Pteridophora alberti befindet.

Herr Kollibay (Neifse) hat ein merkwürdiges Nest einer Schwalbe, Hirundo rustica, eingeschickt. Dasselbe wurde auf dem Schiefsplatz in Lammsdorf gesammelt und besteht aus einem Rotschwanzneste ( $R$. tithys), dessen Ränder durch Lehmmörtel etwas abgesteift sind. Es stand in einer Veranda auf einem Brettchen. Die Schwalbe war mehrmals durch Menschenhand verhindert worden, ihr Nest zu bauen und hatte dann das verlassene 'Rotschwanznest für ihre Zwecke notdürftig ausgebaut.

Herr Matschie stellt die Frage, ob es bekannt ist, dafs dem Storch irgendwo kreuzartig über einander befestigte Latten an Stelle eines Wagenrades oder auf Stangen befestigter Reisigbündel zum Aufbau des Nestes dargeboten werden. Den Anwesenden ist darüber nichts bekannt.

Herr Reichenow liest aus einem Berichte des Herrn Dr. Krämer über die Vogelwelt der Samoa-Inseln einige interessante Nachrichten vor.

Herr Schulz zeigt einige von ihm in der Umgegend von Para gesammelte Vogeleier vor, 4 Eier eines Spechtes, wahrscheinlich zur Gattung Celeus gehörig, welche er aus einem Kautschukbaum im tiefen Urwald am Rande eines Baches genommen hatte, und 2 Eier eines ziemlich niedrig im Unterholze brütenden Hockohuhnes.

Herr Schenkling erwähnt zu dem Protokoll über die Februar-Sitzung, dass durch Dr. Braatz die Tuberkulose bei einer grofsen Zahl von Papageien nachgewiesen sei, welche in der Berliner Tierärztlichen Hochschule untersucht waren. 